Pure Sciences

Oral

Abstract ID: 68

\title{
The adsorption behaviour of lysozyme as a potential anti- biofouling agent
}

\author{
Anil Jalaludin $^{\mathrm{a}} \mid$ Phil Bremer $^{\mathrm{b}} \mid$ Brian Monk $^{\mathrm{b}} \mid$ Jim McQuillan $^{\mathrm{b}}$ \\ anternational Islamic University Malaysia \\ ${ }^{b}$ University of Otago, New Zealand
}

Introduction: Biofilms can be problematic or beneficial. Reports on the underlying adsorption in such context-dependent fouling phenomena have been extensive. However, the mechanisms involved is scarce and appears adsorbate or foulant-specific. Methods: In this study, attenuated total reflection infrared spectroscopy was used to probe the solid-liquid interfacial phenomena involving lysozyme for assessing its surface antibacterial actions. Results: Lysozyme preferentially adsorbed more on to the hydrophilic coated ZnSe IR prism than to an uncoated ZnSe IR prism. Data on discrete adsorption rates suggested that lysozyme was adsorbing as multi-layer aggregates on to the ZnSe prism, and showed faster adsorptiondesorption patterns on an uncoated compared to a $\mathrm{TiO}_{2}$-coated $\mathrm{ZnSe} I \mathrm{R}$ prism. A novel phosphate-modified $\mathrm{TiO}_{2}$ coating material for $\mathrm{ZnSe}$ IR prism was prepared as adsorbate which increased the negative charge on the $\mathrm{TiO}_{2}$ surface via $\mathrm{P}-\mathrm{O}-\mathrm{Ti}$ coordinated linkages, increasing the initial rate of lysozyme adsorption. Enhanced adsorption of lysozyme was achieved by increasing both the solution $\mathrm{pH}$ and $\mathrm{NaCl}$ concentration. Maximum adsorption occurred at $\mathrm{pH}$ 11 which corresponded to the protein's isoelectric pH. Conclusions: ATR-IR spectroscopy has proved to be a useful method to study surface adsorption of antibacterial agents such as lysozyme for further explorations into approaches to control biofouled surfaces.

KEYWORDS: lysozyme, adsorption, biofouling, ATR-IR, TiO2, antibacterial 